\title{
Understanding the influence of a parasocial relationship and beauty influencers' credibility on brand credibility and repurchasing intention on the media platform Instagram
}

\author{
F.F. Fadilah \& Y. Alversia \\ Faculty of Economics and Business, Universitas Indonesia, Jakarta, Indonesia
}

\begin{abstract}
Nowadays, digital influencers are being hired by many companies to market their brands in the form of electronic word of mouth strategy. The companies do this because they consider this as a tool to provide information about their brands to a broader section of people. This study investigates how the perceived attributes of digital influencers on Instagram can influence their parasocial relationship and credibility that could impact brand credibility and repurchasing intention of consumers. This study employed a quantitative approach with a total of 243 samples. The data were collected using purposive sampling and analyzed using the structural equation method (SEM). It was found that attractiveness and attitude homophily were positively related to the parasocial relationship and influencers' credibility. On the other hand, influencers' credibility was positively related to brand credibility. It was shown that brand credibility and parasocial relationship positively influenced consumers' repurchasing intention. However, no significant effect of influencers' credibility on the other variables can be found.
\end{abstract}

\section{INTRODUCTION}

The increasing use of technology and the internet, including the use of social media, makes communication and information easier to access. Many businesses take advantage of social media as a marketing strategy to advertise or promote their products to attract and retain users. Constantinides (2014) produced a marketing strategy through passive and active approaches, who explained that an active approach is a strategy that implements social media as a marketing and public relation platform. In this case, Childers, Lemon, and Hoy (2018) explain that it can be done by making digital influencers as endorsers of a company's brand or products. Non-celebrity endorsers, according to Abidin (2016), are known by only a certain group of people and are considered to have more power in the online context because they are considered to be more credible and approachable (Djafarova and Rushworth, 2017). The non-traditional celebrities will then be referred to as a social media influencer in the realm of social media.

Many people who followed a social media influencer feel that there is a strong social relationship between them. This is called a parasocial relationship. A parasocial relationship can be predicted from several determinants, including attractiveness and attitude homophily. According to Colliander and Dahlen (2011), when the followers feel that they have similarities with digital celebrities, along with repeated exposures to the latest content uploaded on their social media, the digital celebrities will be perceived as a reliable source of information and their advertisement will be viewed as a credible purchasing information that will influence their purchasing decision assessment. Influencers who are used as a form of communication tool will construct the credibility they have as a measurement of the credibility of the brand that they are promoting. In other words, the credibility of an endorser will be transferred to the brand being promoted (Wang et al., 2017). In this case, parasocial relationships, influencers' credibility, and brand credibility will lead users to want to purchase the product. In this study, purchasing intention will be intended for those who have previously purchased a product or have a repurchasing intention. 
The purpose of this study was to see the extent of influence that the beauty influencers have as communicators between the brand and their followers on their Instagram page. It was conducted by investigating the parasocial relationship and the credibility of beauty influencers from their followers, which could influence the brand credibility. In addition to the influence of the parasocial relationship, the credibility of a beauty influencer, and brand credibility on repurchasing intention of the products promoted by the beauty influencer, this study also identifies the establishment of a long-term relationship between the brand or products and their consumers.

\section{LITERATURE REVIEW}

The theory of the parasocial relationship was first introduced by Horton and Wohl (1956) and was originally defined as an experience of a face-to-face relationship between the audience and performers on television, movie, and radio. Nowadays, a parasocial relationship is inferred as psychological associations built by media users unilaterally with the characters or celebrities of the media being used. A parasocial relationship can be seen from several determinants, including attractiveness. It occurs because social media influencers have an attractive value and have something in common with their followers (Giles, 2002). In this case, Rubin and Step (2000) divided attractiveness into physical and social attractiveness. Another determinant used in a parasocial relationship is the attitude homophily or the similarity of behavior between the beauty influencers and their followers (Giles, 2003; Eyal and Rubin, 2003; Lee and Watkins, 2016). Therefore, the following hypotheses were developed:

H1: Physical attractiveness has a significant positive effect on the parasocial relationship.

H2: Social attractiveness has a significant positive effect on the parasocial relationship.

H3: Attitude homophily has a significant positive effect on the parasocial relationship.

Credibility is defined as a source that is perceived as having knowledge, skill, or experience relevant to a communication topic and can be trusted to give an unbiased opinion or present objective information on the issue (Belch and Belch, 2012). Credibility is one of the important characteristics in which the audience can feel that the communicator has an impact on their decision to purchase products. Physical attractiveness in the beauty industry can be considered as an important selling point. On the other hand, attitude homophily or similarity in behavior can also be considered as a determinant factor of credibility because of the perceived value shared between the followers and the influencers (Sokolova and Kefi, 2019). Therefore, the following hypotheses were developed:

H4: Physical attractiveness has a significant positive effect on beauty influencers' credibility. H5: Attitude homophily has a significant positive effect on beauty influencers' credibility.

Influencers who are used as a form of communication tool will make their credibility as a measure of the credibility of the brand they are promoting. Brand credibility is the believability of the position of a product owned by a brand. The credibility of a brand depends on the willingness and ability of the company to deliver what has been promised (Erdem et al., 2006). According to Wang et al. (2017), when the endorsement consists of several signals from the brand being promoted, the credibility of the endorser will then be transferred to the brand. Therefore, the following hypothesis was developed:

H6: The credibility of beauty influencers has a significant positive effect on the credibility of the brand being promoted.

Repurchasing intention is a decision made by an individual to repurchase a product or a service from the same company by considering the current and possible circumstances (Hellier et al., 2003). In this study, repurchasing intention was used as a form of anticipation if consumers or respondents have previously made purchases of products or brands that are promoted or recommended by the beauty influencers even before the influencer promotes or recommends it. Sokolova and Kefi (2019) stated that the parasocial relationship and the credibility of beauty influencers can influence 
their followers to buy the product being promoted if the influencers could be relied on and trusted (Wathen and Burkell, 2002). Meanwhile, brand credibility, according to Jeng (2016), is a signaling tool that can increase consumer's decision confidence and increase their buying interest. Therefore, the following hypotheses were developed:

H7: The parasocial relationship has a significant positive effect on the repurchasing intention of the product being promoted.

H8: The credibility of beauty influencers has a significant positive effect on the repurchasing intention of the product being promoted.

H9: Brand credibility has a significant positive effect on the repurchasing intention of the product being promoted.

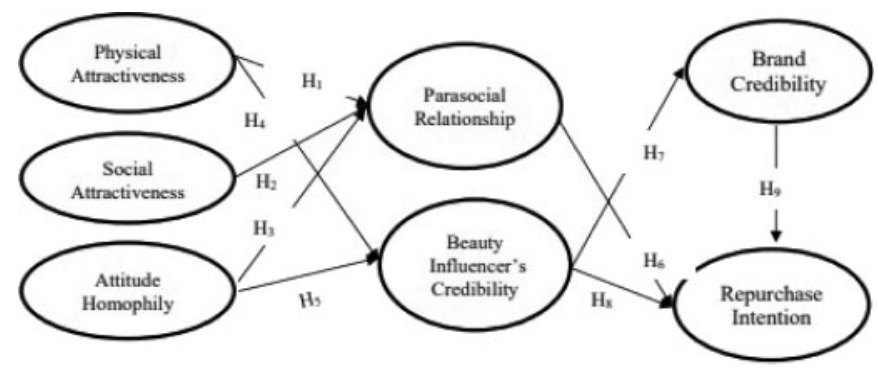

Figure 1. Research model.

\section{RESEARCH METHOD}

A quantitative approach was used in this study by conducting surveys through online questionnaires, and the results were analyzed using the Likert scale $1-6(1=$ strongly disagree; $6=$ strongly agree $)$. This study was conducted in Indonesia, consisting of all active users of Instagram without gender restrictions. Using the purposive sampling technique, sampling will be determined by several characteristics such as the following: at least 18 years old, an active user of Instagram, a follower of at least one beauty influencer on Instagram, and has bought beauty and body care products (makeup, skincare, or sun care) that has been promoted or recommended by the beauty influencer on Instagram in the last six months. Within a week of data collection, 277 respondents had filled out the survey. After the screening process, 243 surveys were selected to be used in this study.

\section{RESULTS AND DISCUSSION}

To test the hypotheses, this study employed a structural equation model (SEM) using AMOS 24. Physical attractiveness $(C . R=4.628, p<0.001)$, social attractiveness $(C . R=3.409$, $\mathrm{p}<0.001)$, and attitude homophily $(\mathrm{C} . \mathrm{R}=4.361, \mathrm{p}<0.001)$ showed a significant positive effect on the parasocial relationship between beauty influencers and their followers. Physical attractiveness and attitude homophily also showed a significant positive effect on the influencers' credibility, with values of C.R $=6.841, p<0.001$ and C.R $=5.601, p<0.001$, respectively. Influencers' credibility $(C . R=6.364, p<0.001)$ showed a significant positive effect on brand credibility, but not on repurchasing intention $(C . R=0.027, p>0.500)$. However, repurchasing intention was influenced by both the parasocial relationship $(C . R=3.062, p<0.005)$ and brand credibility $(C . R=8.026$, $\mathrm{p}<0.001)$. Most of the proposed hypotheses are supported, except for H8.

A parasocial relationship could influence a repurchasing intention from a user or a follower because from this relationship, audiences or followers can feel that they have the same values and 
behavior as the beauty influencers. Therefore, they will feel the closeness to those influencers and will buy products because of the perceived closeness, which is stated and conceptualized (Sokolova and Kefi, 2019). Influencers here are also endorsers and the endorsement consists of several signals from a brand being promoted. Therefore, the influencers' credibility will be transferred to the promoted brand (Wang et al., 2017). According to Swait and Sweeney (2008), brands can provide additional value to companies, one of which is increasing the bond between the company and consumer, leading to a long-term relationship. In other words, it can be said that high brand credibility can increase consumer's commitment and sustainability.

\section{CONCLUSION AND IMPLICATION}

The results of this study showed that repurchasing intention was only affected by the parasocial relationship and brand credibility and not by influencer's credibility. It was found that companies that were using Instagram as a platform and beauty influencers as endorsers of their product or brand could be benefited from a parasocial relationship built by the beauty influencer with their followers, which would lead to a long-term relationship between companies and their consumers. The findings are expected to be useful for the beauty influencers to develop their ability to promote and recommend the beauty products or brands they use to influence their followers on Instagram.

\section{REFERENCES}

Abidin, C. (2016). Visibility labour: Engaging with In?uencers' fashion brands and \#OOTD advertorial campaigns on Instagram. Media International Australia, vol. 161, issue 1.

Belch, G. E., \& Belch, M. A. (2012). Advertising and Promotion. An Integrated Marketing Communication Perspective. 10th ed., McGraw-Hill, Boston.

Childers, C. C., Lemon, L. L., \& Hoy, M. G. (2018). \#Sponsored \#Ad: Agency perspective on in?uencer marketing campaigns. Journal of Current Issues \& Research in Advertising, vol.1, issue 17.

Colliander, J., \& Dahlen, M. (2011). Following the fashionable friend: The power of social media - Weighing Publicity effectiveness of blogs versus online magazines. Journal of Advertising Research, vol. 51.

Constantinides, E. (2014). Foundation of Social Media Marketing. Procedia-Social and Behavioral Sciences, vol. 148.

Djafarova, E., \& Rushworth, C. (2017). Exploring the credibility of online celebrities' Instagram pro?les in in?uencing the purchase decisions of young female users. Computers in Human Behavior, vol. 68.

Erdem, T., Swait, J., \& Valenzuela, A. (2006). Brand as Signals: A Cross-Country Validation Study. Journal of Marketing, vol. 70, issue 1.

Eyal, K., \& Rubin, A. M. (2003). Viewer aggression and homophily, identification, and parasocial relationships with television characters. Journal of Broadcasting \& Electronic Media, vol. 47, issue 1.

Giles, D. C. (2002). Parasocial interaction: a review of the literature and a model for future research, Media Psychology, vol. 4.

Hellier, P. K., et al. (2003). Customer Repurchase Intention: A General Structural Equation Model. European Journal of Marketing, vol 37, issue 11/12.

Jeng, S. (2016). The influences of airline brand credibility on consumer purchase intentions. Journal of Air Transport Management, vol. 55.

Lee, J. E., \& Watkins, B. (2016). YouTube vloggers' influence on consumer luxury brand perceptions and intentions. Journal of Business Research, vol. 69, issue 12.

Rubin, A. M., \& Step, M. M. (2000). Impact of motivation, attraction, and parasocial interaction on talk radio listening. Journal of Broadcasting \& Electronic Media, vol. 44, issue 4.

Sokolova, K., \& Kefi, H. (2019). Instagram and YouTube bloggers promote it, why should I buy? How credibility and parasocial interaction influence purchase intention, Journal of Retailing and Consumer Services.

Wang, S. W., Kao, G. H., \& Ngamsiriudom, W. (2017). Consumers' attitude of endorser credibility, brand and intention with respect to celebrity endorsement of the airline sector. Journal of Air Transport Management, vol. 60 .

Wathen, C. N., \& Burkel, J. (2002). Believe it or not: Factors Influencing Credibility on the Web. Journal of American Society of Information Science and Technology, vol. 53, issue 2. 